\title{
Acculturation and use of traditional medicine among African migrant women in Sydney: a mixed method study
}

Zewdneh Shewamene ${ }^{1,2^{*}}$, Tinashe Dune ${ }^{3}$ and Caroline A. Smith ${ }^{2,4}$

\begin{abstract}
Background: More than $80 \%$ of the African population depend on traditional medicine as a primary healthcare. Although the African migrant community is increasing in Australia, there is no research documenting if and how African migrant communities have maintained or changed their use of traditional health practices after migration. This study aims to answer the following research questions: does acculturation influence the use of traditional medicine? and how are cultural health practices or beliefs manifested among African migrant women in Australia?
\end{abstract}

Method: A mixed methods design which involved a cross-sectional survey $(n=319)$ and individual interviews $(n=15)$ was conducted. Survey data were analysed using SPSS (version 23) and logistic regression model was used to test associations. Qualitative data were analysed thematically using NVivo 11 software to identify themes and conceptual categories in the participants' responses. The study was informed by acculturation theory.

Result: Both the survey and the interview data indicated that cultural health practices were retained as an important form of healthcare for African migrant women in Sydney. The findings indicated that African migrants continued to use traditional medicines as part of their cultural identity and to build cohesive ethnic community to share traditional values and cultural practices. Women who relatively stayed for shorter period of time in Australia and migrated at a later age were more likely to use TM.

Conclusion: Acculturation proxy measures increased the likelihood of TM use suggesting African migrant women retain their cultural health practices in Australia and use of TM was manifested as part of their cultural identity. The findings have implications to improve the provision of culturally sensitive and responsive health services when caring for African migrant women.

Keywords: Acculturation, Traditional medicine, African women, Migrants, Australia

\section{Background}

As defined by the World Health Organization [1], traditional medicine in this study refers to "the sum total of the knowledge, skills and practices based on the theories, beliefs and experiences indigenous to different cultures, whether explicable or not, used in the maintenance of

\footnotetext{
*Correspondence: zeedshow@gmail.com

${ }^{2}$ NICM Health Research Institute, Western Sydney University, Penrith, NSW 2751, Australia

Full list of author information is available at the end of the article
}

health, as well as in the prevention, diagnosis, improvement or treatment of physical and mental illnesses". Similarly, this study adopted the National Centre for Complementary and Integrative Medicine (NCCIM) definition for complementary and alternative medicine which states "group of diverse medical and health care systems, practices, and products that are not generally considered part of conventional medicine" [2].

Traditional medicine (TM) is an important component of the primary healthcare in Africa [3, 4]. Reports 
estimated that between 70 and $95 \%$ of the population in developing countries use TM $[5,6]$. Greater than $80 \%$ of the African population use TM as a first line of health [3]. There are various suggested explanations for high utilisation of TMs. Scholars point to the conventional health care in Africa which has limitations of accessibility, availability and affordability to most of the population [7, 8]. In contrast, TM tends to be more affordable with both direct and indirect costs, easily accessible in villages, and individuals can self-apply them $[9,10]$.

Studies have suggested that when people migrate or arrive as refugee to a different country, they may take with them existing health beliefs and practices [11-13]. As such, in addition to using health care services offered in their new destination, migrants often practice their own traditional health remedies that they have brought with them [11, 14]. Currently, there is a lack of research that examines whether the use of TM in Africa also continues among migrant African communities in Western countries.

The extent to which such cultural health practices and beliefs are maintained, or changed, as people move from their native countries to new ones is important in addressing transcultural perspectives of migrants. In turn, this may help understand the needs of racial and ethnic minorities such as delivery of culturally appropriate health services, health seeking behaviors, compliance with treatment and attendance of health education programs [15].

Findings from a systematic review reported that women in Africa are extensively dependent on cultural health practices [16]. However, the experiences of these women after they resettle in Western countries, where biomedical care is predominant, remains largely unexplored. With the number of African ethnic minorities increasing in Australia [17, 18], this paper aims to answer the following research questions: 1) does acculturation affect the use of TM among African migrant women in Australia? and 2) how are their cultural health practices or beliefs manifested? in Australia? The study was informed by the acculturation theory to better understand how traditional health practices and beliefs change over time among African migrants.

\section{Methods}

\section{Study design}

This study used a mixed-method design which involved a cross-sectional survey and individual interviews. Combining quantitative and qualitative methods was important to strengthen the overall research design, utilizing the strengths of both approaches and generating more comprehensive and rich contextual data [19-21]. The criticism that qualitative research is subjective and provides few opportunities for generalisation across a large population can be overcome by quantitative methods that provides data on frequency of concepts or constructs from a representative sample [22-24].

The survey explored the influence of acculturation on use of TM considering women's age at arrival, length of residency in Australia, and English language fluency. The interview examined in more detail women's experiences and perceptions of using traditional after resettlement in Australia.

\section{Participants and sampling strategy}

African migrant women residing across the Sydney metropolitan area who were born in Africa, aged $\geq 18$ years, speak at least basic English Language (based on self-rated responses as 'advanced', 'basic', or 'limited'), and had been a resident in Australia for at least 12 months were eligible to participate. Women who were in Australia on short term work or holiday visas were excluded.

Sample size determination for this survey was based on the need to ensure an adequate sample that permitted analysis of associations between specific predictor variables and use of traditional medicine. In a priori power analysis, the necessary sample size was computed as a function of user-specified values for the required significance level $\alpha$, the desired statistical power $1-\beta$, and the to-be detected population effect size [25]. A G*Power software program which is common in the social, behavioral, and biomedical sciences, was used to determine the required sample size in this study [25]. Accordingly, a total sample size of 299 subjects was required to detect moderate effects size of 0.20 [26] with $80 \%$ power and assuming 4 degrees of freedom when using Chi-square test of associations between key demographic or acculturation factors and use of traditional medicine.

When survey participants completed the questionnaires, they were invited to participate in follow up individual interviews. In addition to the inclusion criteria outlined under the survey, interview participants were selected purposively if they have previous experience of using traditional and complementary medicine. Fifteen eligible women were interviewed. After 13 interviews, no new themes emerged which indicated saturation was achieved.

Ethical approval was received from Western Sydney University Human Research Ethics Committee (ref: H1196). Informed consent was obtained from all women who participated in the study.

\section{Study promotion and recruitment procedures}

The study was promoted through community consultations and networking with community associations, multicultural organisations, and business firms which 
were affiliated with the African communities in Sydney. Posters and flyers were displayed in prominent places including; shopping centers, train and bus stations, entertainment places, University and College campuses, restaurants, cafes, and African hair salons. For women expressing interest in the study, a link to the online questionnaire was sent through email, text messages and social media (Facebook, WhatsApp, and Viber). Optionally, paper-based questionnaires were hand delivered to individuals attending the organisations. A total of 332 women were sent the link to the online survey. A total of 302 paper-based questionnaires were distributed by hand. In total, 634 survey questionnaires were distributed using both the online and paper-based approaches. Of these, 348 (54.9\%) surveys were returned (205 online and 143 paper-based). Of these, 29 questionnaires (25 online and 4 paper-based) were not fully completed, and therefore were disregarded, leaving a total number of 319 questionnaires to be analysed.

\section{Data collection and measures}

Data was collected between October 2017 to January 2018. The survey explored socio-demographic characteristics including age, marital status, pregnancy and birth, income, education and employment status, religion, and country of origin were collected. The questionnaire was developed in English language and contained a total of 33 questions and completion time was approximately 15 min.

The survey also explored acculturation and patterns of TM use since migration to Australia. There were no standardised survey tools suitable to assess the use of TM and acculturation among African migrant communities in Western countries. Therefore, the present study developed questions based on findings from a comprehensive literature review [16, 27-31]. Proxy measures of acculturation including. Language, length of stay in Australia, and age at arrival were used in this study. Studies showed that proxy acculturation measures can be useful to assess acculturation in situations where use of a more comprehensive acculturation scale is not available [29, $31,32]$. A combination of $2-3$ proxy measures have been indicated to effectively explore the effects of acculturation on health outcomes with greater flexibility $[28,30]$. The most common proxy measures that have been shown to have high internal consistency were language spoken (during interview or at home), proportion of life lived in the host country, and generational status [30].

A pilot test of the survey was undertaken to examine face validity. The pilot was carried out among eight African-born women. Following the pilot study, several modifications were made including revising terms to improve the readability of the questionnaire.
Based on the survey findings, participants who had used TM were invited to participate in the interview. In total, 33 survey participants nominated their willingness to be interviewed when they completed the survey questionnaires. Of these, 15 eligible women were interviewed as a result of targeting more diversity in the sample to include different country of origin, length of stay in Australia and age. The development of the interview guide was informed by the findings from the survey, and the questioning in the interviews examined in more detail women's experiences of using TM related to acculturation including the meaning of traditional medicine in their culture. Face-to-face and telephone interviews were conducted using a digital audio-recorder and notes were taken during and immediately following the interviews. The interviews were lasted between 40 and $80 \mathrm{~min}$. All audio-recorded interviews were transcribed in full and results presented with pseudonyms.

\section{Data analysis}

Survey data were checked for consistency, coded appropriately, and entered into SPSS software package version 23. Descriptive analysis using frequencies and proportions was conducted to describe the sample characteristics and distribution of variables. The relationship between TM use and acculturation factors was examined using binary logistic regression model. For all significance tests a $p$-value of 0.05 or less and a $95 \%$ confidence interval were used to quantify the associations between acculturation variables and use of TM. Bivariate logistic analysis was initially conducted with potential predictor variables to establish their association with use of TM. Following the bivariate analysis, multivariate logistic regression analysis was conducted to control for possible confounding variables and to compute the adjusted odds ratios (OR) for the explanatory variable. All variables with a $p$-value of less or equal to 0.25 were selected and entered simultaneously into a logistic regression model because the traditional level of 0.05 can fail to identify important variables [33]. A stepwise backward elimination method was employed to eventually produce the most parsimonious model. In backward elimination method, variables with greater $p$-value were sequentially eliminated until all variables in the model were $p<0.05$ [34].

Qualitative data were analysed thematically using NVivo 11 software program [35] to identify themes, conceptual categories, commonalities, and differences in the participants' responses. The analysis started by listening to the recoded audio and reading and re-reading the transcripts several times [36]. This process of familiarisation or immersion into the data helped the researcher to reflect on the entirety of the data and better understand 
and interpret the women's views about TM. The next step was generating codes and using NVivo 11 to produce a concise matrix of key emerging ideas. Finally, a coding summary and report was produced with the sub-themes to answer the research questions. The first author conducted the data analysis and generated the summary codes. The second and third authors reviewed the interview transcripts, the coding summary and provided feedback for revisions to coding framework which were then incorporated into the qualitative data analysis by the first author. Pseudonyms have been used to protect the identity of women.

\section{Results}

\section{Characteristics of participants Survey participants}

A total of 319 women came from 43 countries in Africa were participated in the survey. More than half of the study participants $(171,53.6 \%)$ arrived in Australia between the ages of 21 and 31 years. While 55 (20.7\%) arrived in Australia after the age of 30 years, only 5 (1.6\%) women migrated to Australia at the age of less than 10 years. Of the 319 participants, 111 (34.8\%) were recent settlers (5 years or less) whereas 208 (65.2\%) were long term settlers (greater than 5 years). One hundred twentyfour $(38.9 \%)$ respondents migrated to Australia through the family or partner visa stream. Approximately onethird $(100,31.3 \%)$ of the participants resettled through a Humanitarian and refugee visa pathway. Currently, 130 (40.8\%) women were citizens of Australia, while 123 (38.6\%) were permanent residents (Table 1).

\section{Interview participants}

Women in the interview also had diverse backgrounds from different regions in Africa, such as Nigeria, Cameroon, and Sierra Leone, in West Africa; Ethiopia, and Tanzania in East Africa; Rwanda and Gabon in Central Africa; Sudan in Northern Africa; and Zimbabwe in Southern Africa. The majority of participants had arrived to Australia on Family Visas (Table 2).

\section{The influence of acculturation on use of traditional medicine}

This section presents the integrated findings of the survey and interview data related to the influence of acculturation on use of TM among African migrant women. Generally, African migrant women retain the use of TM in Australia and they viewed it as part of their cultural identity.

Use of traditional or complementary medicines was high with 232 (72.7\%) women using some form of traditional or complementary medicine (Table 3 ). The multivariate logistic regression analysis (Table 3 ) demonstrated
Table 1 Characteristics of survey participants

\begin{tabular}{|c|c|c|}
\hline Characteristics & & n (\%) \\
\hline \multirow[t]{4}{*}{ Age on arrival } & Less than 10 years & $5(1.6)$ \\
\hline & 11-20years & $77(24.1)$ \\
\hline & 21-30years & $171(53.6)$ \\
\hline & Above 30 years & $55(20.7)$ \\
\hline \multirow[t]{2}{*}{ Time spent in Australia } & $1-5$ years & $111(34.8)$ \\
\hline & $>5$ years & $208(65.2)$ \\
\hline \multirow{4}{*}{$\begin{array}{l}\text { Visa pathway to come to } \\
\text { Australia }\end{array}$} & family or partner & $124(38.9)$ \\
\hline & Humanitarian or refugee & $100(31.3)$ \\
\hline & Student & $56(17.6)$ \\
\hline & Skilled/work & $39(12.2)$ \\
\hline \multirow[t]{4}{*}{ Current visa status } & Citizen & $130(40.8)$ \\
\hline & PR & $123(38.6)$ \\
\hline & Temporary & $60(18.8)$ \\
\hline & Refugee or asylum seeker & $6(1.9)$ \\
\hline \multirow[t]{3}{*}{ Self-rated English proficiency } & Fluent & $28(8.8)$ \\
\hline & Excellent & $169(53)$ \\
\hline & Good or fair & $122(38.2)$ \\
\hline \multirow[t]{9}{*}{ Country of origin } & Ethiopia & $58(18.2 \%)$ \\
\hline & Ghana & $13(4.0 \%)$ \\
\hline & Liberia & $10(3.1 \%)$ \\
\hline & Nigeria & $26(8.2 \%)$ \\
\hline & Sierra Leone & $18(5.6 \%)$ \\
\hline & South Sudan & $16(5.0 \%)$ \\
\hline & Sudan & $51(16.0 \%)$ \\
\hline & Zimbabwe & $18(5.6 \%)$ \\
\hline & Other 35 countries & $109(34.2 \%)$ \\
\hline
\end{tabular}

that age on arrival, length of residency in Australia and English language proficiency were predictive acculturation factors of TM use among African migrant women in Australia. Women who migrated to Australia at the age of 20 or older were approximately 3.0 (95\% CI, 1.545.33; $p<0.001$ ) times more likely to use TM than those who arrived before the age of 20. Living in Australia for less than 5 years was significantly associated with an increased use of TM among African migrant women (OR, 3.1; 95\% CI; 1.4-6.68; $p=0.004$ ). Women with less English language fluency were 5.6 times more likely to use TM $(95 \%$ CI; $2.58-12.11 ; p<0.001)$.

The qualitative data analysis indicated that African migrant women retained their traditional health practices and beliefs despite greater access to conventional medical care in Australia. Some participants reported that they were using TM to a greater extent when they were new to Australia. For example, a participant who has been in Australia for the past 11 years commented:

When I first came here [Australia] I had issues with delay [ed] medical attention mainly because 
Table 2 Characteristics of interview participants

\begin{tabular}{|c|c|c|c|c|c|c|}
\hline S. no & Name (age) & $\begin{array}{l}\text { Age at arrival in } \\
\text { Australia }\end{array}$ & $\begin{array}{l}\text { Length of time in } \\
\text { Australia, in year }\end{array}$ & Religion & Visa type on entry & $\begin{array}{l}\text { English } \\
\text { proficiency } \\
\text { (Self rated) }\end{array}$ \\
\hline 1 & Fiona (59) & 38 & 21 & Christian & Humanitarian /Refugee & Good \\
\hline 2 & Zena (62) & 30 & 32 & Catholic & Humanitarian /Refugee & Excellent \\
\hline 3 & Soy (46) & 38 & 8 & African traditional & Skilled/work & Good \\
\hline 4 & $\operatorname{Sim}(33)$ & 22 & 11 & Christian & Family/partner & Good \\
\hline 5 & Anna (42) & 32 & 10 & Christian & Humanitarian /Refugee & Excellent \\
\hline 6 & Tia (28) & 26 & 2 & Christian & Student & Good \\
\hline 7 & Mary (48) & 18 & 30 & Christian & Humanitarian /Refugee & Excellent \\
\hline 8 & Eva (28) & 26 & 2 & Christian & Student & Fluent \\
\hline 9 & Saly (48) & 26 & 22 & Christian & Family/partner & Excellent \\
\hline 10 & Hiva (30) & 19 & 11 & Christian & Family/partner & Excellent \\
\hline 11 & Ney (30) & 10 & 20 & Christian & Family/partner & Fluent \\
\hline 12 & Mire (25) & 23 & 2 & Christian & Skilled/work & Good \\
\hline 13 & Lita (35) & 32 & 3 & Christian & Family/partner & Excellent \\
\hline 14 & Jay (26) & 10 & 16 & Christian & Student & Good \\
\hline 15 & Ema (25) & 20 & 5 & Muslim & Family/partner & Good \\
\hline
\end{tabular}

Table 3 Multivariate logistic regression analysis for acculturation factors and use of traditional medicine

\begin{tabular}{|c|c|c|c|c|c|c|c|}
\hline \multirow[t]{2}{*}{ Variables } & & \multirow[t]{2}{*}{ Total } & \multicolumn{2}{|l|}{ Use of TM } & \multirow[t]{2}{*}{${ }^{\text {a Adjusted OR }}$} & \multirow[t]{2}{*}{$95 \% \mathrm{Cl}$} & \multirow[t]{2}{*}{$P$-value } \\
\hline & & & Yes & No & & & \\
\hline \multirow[t]{2}{*}{ Age on arrival } & $<20$ years & 82 & $40(48.8 \%)$ & $42(51.2 \%)$ & 1 & - & - \\
\hline & $>21$ years & 235 & $192(81.0 \%)$ & $45(19.0 \%)$ & 2.9 & $1.54-5.33$ & $<0.001$ \\
\hline \multirow[t]{2}{*}{ Time spent in Australia } & $<5$ years & 111 & $100(90.1 \%)$ & $11(9.9 \%)$ & 3.1 & $1.4-6.68$ & 0.004 \\
\hline & $>5$ years & 208 & $132(63.5 \%)$ & $76(36.5 \%)$ & 1 & - & - \\
\hline \multirow[t]{2}{*}{ Self-rated English proficiency } & Good & 122 & $112(92 \%)$ & $10(8 \%)$ & 5.6 & $2.58-12.11$ & $<0.001$ \\
\hline & Excellent & 169 & $101(59.8 \%)$ & $68(40.2 \%)$ & 1 & - & - \\
\hline
\end{tabular}

${ }^{a}$ Adjusted ORs were calculated by controlling the refugee status of women (refugee or non-refugee) and women's current migration status in Australia (citizens or non-citizens) which were not found significant during the bivariate analysis

I wouldn't be comfortable, or I wouldn't be able to express myself. I use [d] more traditional medicine instead. So yeah, it is something that changes over time may be because of the time I have been here, I sort of now seek medical help as quick as I can (Sim, $30 \mathrm{y} / \mathrm{o}$ ).

Another woman who has been in Australia for 32 years commented that during her first years of resettlement in Australia she preferred TM over conventional medical care because of her limited experience in navigating the health care system. Gradually she started to look to both health care systems even though she was unable to access some of her cultural traditional therapies that she knew in Africa.

As time goes on, I am not too much into it [traditional medicine] as I was before in Africa or when I was new to Australia. Right after I came here I was just looking around many herbal clinics or the Chinese shops and asking people where to find these traditional doctors. But when I couldn't find these things like in Africa, I actually prepare them by myself, at least some of them. But you know, gradually I am also depending on medications because I learn more about the health system in Australia which is very good and you don't need to pay for it. So I am a kind of combining the both now. When I compare myself now and by the time I arrive to Australia long years ago, I am a bit depend [ent] on both medications and traditional medicine (Zena, 62 $y / o)$.

Respondents also reiterated that TM could be a means for social cohesiveness among family and friends to share traditional values and cultural practices.

Many people try to bring their own traditional med- 
icines and cultural foodstuffs when they go there [in Africa]. Some friends give me some medicines, like herbal ones, when they come from their village in Africa. They will give you something [families and friends], they share with you. If they bring some natural medicine from Africa, it is common for some people to share for someone else. Well it's not actually a lot who bring it to Australia, but still people do bring it here and you can find people who can share for you if you really need it most (Ema, 25y/o).

In other cases, long term residents had a tendency to use both conventional and traditional health care. For example, Zena, whose been in Australia for 32 years stated, "I still do believe in traditional medicines, but again I do believe again taking western medicines if needed."

For Sally the situation was different. Even though she has been in Australia for 22 years, she sometimes used TM that she learnt about from her parents. She also recalled how she had longed for the African version of TM available in Australia and the interaction with African traditional healers.

I missed it [traditional medicine] a lot. I like the casualness, and the easy-going, and the connection with traditional healers. I still use some traditional medicine because I think it's more also the connection that is who you are. So to be connected to your culture, and to you, what your mum was doing, what your dad was doing, it brings memory, and it does make you actually closer to home, to where you come from (Saly, 48 y/o).

TM was deeply rooted and accepted in most African cultures. The interview participants pointed out how traditional health practices were important to them as a health choice and the need to continue these practices across generations.

I will say to keep the originality of the culture. It's a part of our balance. So we need to keep it alive, because it has a kind of effectiveness. We used to live with it before, a long, long time ago. (Soy, 46 y/o).

Participants also noted that in most African cultures, the knowledge and experience related to TM was orally transferred to the new generation. Lita said, "so this traditional medicine has passed through a generation, so it's like a generation passed and it has a healing power." Another participant also stated:

Most of the recipes are well known with most of the elders in the family. It's more like when you have your own recipe that you use but it's something that originates from our culture. That has been tried and used for such purposes. This knowledge will be passed down to the new generation by oral means (Eva, 28 y/o).

\section{Discussion}

While specific acculturation proxy measures including older age at migration and short duration of residence increased the likelihood of TM use, African migrant women retain their cultural health practices in Australia. Overall, the use of TM was manifested as part of their cultural identity and cultural practices. Participants expressed their strong desire to maintain and pass along their cultural heritage about traditional medicine to their next generation.

We found that women who arrive in Australia after the age of 20 years are more likely to use traditional therapies than those who arrive at earlier age. This difference by age at arrival can potentially be explained by the limited exposure and adaptability of older migrants to the new lifestyles in Australia, as a result they may retain their cultural health practice and beliefs. This is in line with a previous study which documented that older migrants are less likely to acculturate or build new social networks and the presence of a network of people of the same ethnicity is likely to delay or inhibit acculturation [37]. Conversely, young migrants are more likely to be exposed to the lifestyles of their native-born counterparts and willing to acculturate [38].

In this study, shorter duration of residence in Australia was a significant predictive of TM use among African migrant women. This finding is consistent with a study among Asian-Americans that indicated those spent the majority of their life in US are less likely to use ethnicspecific complementary and alternative medicine [39]. This may be partly explained by the fact that women recently arrived in Australia may have a limited level of adaptation with the Western conventional medical care and, as a result, may stick to their traditional health practices and beliefs.

We also found that women who self-rated their English proficiency as low were more likely to use TM. This finding is in agreement with a study by Hsiano and colleagues that reported less English proficiency was related to greater ethnic-specific complementary and alternative medicine use among Asians and Latinos in US [40]. A possible explanation for our result may be the impact of language to navigate the conventional healthcare system in Australia [41] in which less English proficiency may limit women's ability to effectively utilise available health services. This situation may lead to reliance on traditional alternative therapies that women can self-prescribe in most case [42]. 
The results from this study highlight the role cultural heritage plays in the use of TM among African migrant women. Interview findings found a strong desire to maintain and pass along their cultural heritage including TM. It seems possible that these results are due to the fact that TM has a significantly longer history than Western medicine in Africa and, as a result, most African culture is largely intertwined with it $[16,43]$. In addition, women's lack of previous experience in accessing modern health services in Africa may partly explain why they adhere to their cultural health practices and beliefs in Australia. Studies have shown that refugee and migrant women's previous experiences in accessing health care influenced how they access the services in the new countries [41]. For example, Mengesha and colleagues found that refugee and migrant women's participation in health promotion services were compromised by lack of previous experiences [41].

The impact of culture on health-related beliefs is complex and one's attitudes and beliefs about health and disease are clearly shaped by the culture to which one belongs [44, 45]. Acculturation theory indicates that the stronger people identify with their traditional heritage, the greater the chance they will follow traditional health practices and beliefs derived from their cultures [46]. The use of culturally grounded traditional health practices and beliefs is related to a complex interaction of beliefs, values, perceptions, and religious and cultural orientations [46]. In general, this finding opposes the prediction that cultural health practices and beliefs will become a thing of the past when migrants move to a new destination country with a significant cultural variation. However, women use traditional medicine at a different level when specific migration factors are considered. For example, women who had stayed in Australia for shorter periods, moved to Australia at a later age, and have less English language proficiency were relatively high users of traditional medicine. This finding partly corroborates the preposition that groups and individuals who acculturate more slowly are more likely to rely on their cultural health practices [44]. As such, the use of acculturation theory in this study helped better explain the influence of acculturation on the use of traditional health practices of ethnic minorities such as African migrant women in Australia.

The implications of this study increase our understanding of how traditional health practices and beliefs are changed or maintained after African women resettled in Sydney. This is important to help develop culturally responsive approaches and community/population focused health partnerships with women from diverse ethnic, cultural, or language groups. Furthermore, these study findings will be of interest to policy makers and healthcare providers planning and delivering services for African migrant women.

\section{Limitation of the study}

These findings must be considered in the context of the study's limitations. Although multidimensional measures of acculturation provide a more comprehensive understanding of acculturation and its association with health outcomes, this study used proxy measures of acculturation. Since variables used to measure acculturation in one ethnic group may not work well in describing acculturation in other groups, use of proxy measures offer more flexibility than scale-based measures [31]. Studies also suggested that proxy measures are also effective in measuring different dimensions of acculturation [28, 31]. Another limitation of this study was that we did not explore the differences between African ethnic or cultural groups in terms of TM use and acculturation. We acknowledge that African migrant women in Australia represent diverse ethnic and cultural backgrounds. However, they still share some level of similarity within the Australia context, in terms of racialisation (despite their varying appearance), by geography (from Africa), culture (largely communal), and migration experience (having left Africa). Finally, generalisability of the study can be limited due to the fact that participants were required to speak at least basic English language and that may have led to a biased sample selection.

\section{Conclusion}

TM is generally retained as an important form of health care by African migrant women in Sydney. Given that acculturation is a process in which African-born women's health beliefs may change over time with an inclination towards the new culture in Australia, less acculturated women seem to rely more on TM. Findings from this study may have implications to better understand the transcultural perspectives of African migrants related to their cultural health practices and beliefs. In turn, this may enhance delivery of culturally appropriate health services and health education programs in Australia.

\section{Acknowledgements \\ The authors would like to acknowledge multicultural organisations and community associations working with African communities across Sydney who aided in the recruitment of participants. The authors would also like to acknowledge African-born women who provided their time and voices to this research.}

\section{Authors' contributions}

ZS conceived and designed the study with continuous support from TD and CAS. ZS collected the data. All authors involved in data analysis and interpretation. ZS drafted the manuscript. TD and CAS read and revised the manuscript. All authors have read and approved the submission.

Funding

This research has not received any funding. 


\section{Availability of data and materials}

The supporting materials used in this study are contained within the article.

\section{Declarations}

\section{Ethics approval and consent to participate}

Ethical approval was received from Western Sydney University Human Research Ethics Committee (ref: H1196). All the methods were performed in accordance with the Declaration of Helsinki. Informed consent was obtained from all individual participants included in the study.

\section{Consent for publication}

Not applicable.

\section{Competing interests}

ZS was supported by Western Sydney University Postgraduate Research Scholarship to study a PhD program in the NICM Health Research Institute. ZS and CAS declared that as a medical research institute, NICM Health Research Institute receives research grants and donations from foundations, universities, government agencies and industry. Sponsors and donors provide untied and tied funding for work to advance the vision and mission of the Institute. TD declared that they have no conflict of interest.

\section{Author details}

${ }^{1}$ Ethiopian Health Insurance Agency (EHIA), P.O.Box 1176, Addis Ababa, Ethiopia. ${ }^{2} \mathrm{NICM}$ Health Research Institute, Western Sydney University, Penrith, NSW 2751, Australia. ${ }^{3}$ School of Health Sciences, Translational Health Research Institute \& Diabetes Obesity and Metabolism Translational Research Unit Western Sydney University, Penrith, NSW 2751, Australia. ${ }^{4}$ Graduate Research School, Western Sydney University, Penrith, NSW 2751, Australia.

Received: 15 March 2021 Accepted: 17 September 2021

Published online: 06 October 2021

\section{References}

1. World Health Organization. Programme on Traditional Medicine. General guidelines for methodologies on research and evaluation of traditional medicine. Geneva: World Health Organization; 2000.

2. National Center for Complementary and Alternative Medicine: Third Strategic Plan 2011-2015. Retrieved from https://nccih.nih.gov/sites/nccam. nih.gov/files/D347_05-25-2012.pdf. Accessed January 5, 20219.

3. Romero-Daza N. Traditional medicine in Africa. Ann Am Acad Politic Soc Sci. 2002;583(1):173-6.

4. Abdullahi A. Trends and challenges of traditional medicine in Africa. Afr J Trad Complement Altern Med. 2011;8(5):115-23.

5. LuY, Hernandez P, Abegunde D, Edejer T. The world medicines situation 2011. Geneva: Medicine expenditures. World Health Organization; 2011.

6. Kasilo OM, Trapsida JM. Regulation of traditional medicine in the WHO African region. Afr Health Monitor. 2010:25-31.

7. Nelms LW. \& Gorski, J: the role of the African traditional healer in women's health. J Transcult Nurs. 2006;17(2):184-9.

8. Nergard CS, Ho T, Diallo D, Ballo N, Paulsen BS, Nordeng H. Attitudes and use of medicinal plants during pregnancy among women at health care centers in three regions of Mali. West-Africa J Ethnobiol Ethnomed. 2015;11:73.

9. Leach B, Paluzzi JE, Munderi P. Prescription for healthy development: increasing access to medicines: Earthscan; 2005.

10. Innocent E. Trends and challenges toward integration of traditional medicine in formal health-care system: historical perspectives and appraisal of education curricula in sub-Sahara Africa. J Int Ethnopharmacol. 2016;5(3):312-6.

11. Pavlic DR, Brovc M, Svab I, Ahcin J. \& Slajpah, M: attitudes to illness and use of health services by economic immigrants in Slovenia. Croatian Med J. 2007;48(5):675-83.

12. Nguyen LT, Kaptchuk TJ, Davis R. B: the use of traditional Vietnamese medicine among Vietnamese immigrants attending an Urban Community health center in the United States. J Altern Complement Med. 2016:22(2):145-53.
13. Shankar PR, Rose C, Sebastian A. Medical Students'Opinions Regarding Possible Influence of Culture and Social Issues on Health Seeking Behaviour. Educ Med J. 2017:9(1):29-41.

14. Hwang JH, Han DW, Yoo EK, Kim W. Y: the utilisation of complementary and alternative medicine (CAM) among ethnic minorities in South Korea. BMC Complement Altern Med. 2014;14:103.

15. Kreuter MW, Lukwago SN, Bucholtz DC, Clark EM. \& Sanders-Thompson, $\checkmark$ : achieving cultural appropriateness in health promotion programs: targeted and tailored approaches. Health Educ Behav. 2003:30(2):133-46.

16. Shewamene Z, Dune T, Smith C. A: the use of traditional medicine in maternity care among African women in Africa and the diaspora: a systematic review. BMC Complement Altern Med. 2017;17(1):382.

17. The Federation of Ethnic Communities' Councils of Australia: Shared Experience and Learning from African Communities in Australia 2017 Retrieved from http://fecca.org.au/wp-content/uploads/2017/08/Issue46.pdf. Accessed 5 Jan 20219.

18. Australian Bureau of Statistics: Census QuickStats Country of Birth 2016. Retrieved from http://quickstats.censusdata.abs.gov.au/census services/ getproduct/census/2016/quickstat/4105_1GSYD. Accessed 5 Jan 20219.

19. Creswell JW, Klassen AC, Plano Clark VL, Smith K. C: best practices for mixed methods research in the health sciences. Bethesda: National Institutes of Health; 2011.

20. Johnson RB, Onwuegbuzie AJ. Mixed methods research: A research paradigm whose time has come. Educ Res. 2004;33(7):14-26.

21. Creswell J, Creswell J. Research design : qualitative, quantitative, and mixed methods approaches (Fifth edition. ed.). Los Angeles: SAGE; 2018

22. Toomela A. Variables in psychology: a critique of quantitative psychology. Integr Psychol Behav Sci. 2008;42(3):245-65.

23. Gelo O, Braakmann D, Benetka G. Quantitative and qualitative research: beyond the debate. Integr Psychol Behav Sci. 2008;42(3):266-90.

24. Creswell JW, Piano V. L: designing and conducting mixed methods research: JSTOR; 2011

25. Faul F, Erdfelder E, Lang AG, Buchner A. G*power 3: a flexible statistical power analysis program for the social, behavioral, and biomedical sciences. Behav Res Methods. 2007;39(2):175-91.

26. Cohen J. Statistical power analysis for the behavior science. Lawrance Eribaum Association; 1988.

27. Wallace PM, Pomery EA, Latimer AE, Martinez JL, Salovey P. A review of acculturation measures and their utility in studies promoting Latino health. Hisp J Behav Sci. 2010:32(1):37-54.

28. Salant T, Lauderdale D. S: measuring culture: a critical review of acculturation and health in Asian immigrant populations. Soc Sci Med. 2003;57(1):71-90

29. Renzaho AM. Immigration and social exclusion: examining health inequalities of immigrants through acculturation lenses. Theorising social exclusion. Oxon: Routledge; 2009. p. 117-26.

30. CruzTH, Marshall SW, Bowling JM. \& Villaveces, a: the validity of a proxy acculturation scale among US Hispanics. Hisp J Behav Sci. 2008:30(4):425-46.

31. Lee $\mathrm{S}$, Nguyen HA. \& Tsui, J: interview language: a proxy measure for acculturation among Asian Americans in a population-based survey. $J$ Immigr Minor Health. 2011;13(2):244-52.

32. Alegria $M$. The challenge of acculturation measures: what are we missing? A commentary on Thomson \& Hoffman-Goetz. Soc Sci Med. 2009:69(7):996.

33. Bursac Z, Gauss CH, Williams DK, Hosmer D. W: purposeful selection of variables in logistic regression. Source Code Biol Med. 2008;3(1):17.

34. Austin PC, Tu JV. Automated variable selection methods for logistic regression produced unstable models for predicting acute myocardial infarction mortality. J Clin Epidemiol. 2004:57(11):1138-46.

35. Bazeley P, Jackson K. Qualitative data analysis with NVivo: Sage publications limited; 2013.

36. Flick U. The SAGE handbook of qualitative data analysis: SAGE; 2013

37. Roshania R, Narayan K, Oza-Frank R. Age at arrival and risk of obesity among US immigrants. Obesity. 2008;16(12):2669-75.

38. Gibson M. A: immigrant adaptation and patterns of acculturation. Hum Dev. 2001;44(1):19-23.

39. Lee JH, Goldstein MS, Brown ER. \& Ballard-Barbash, R: how does acculturation affect the use of complementary and alternative medicine providers among Mexican-and Asian-Americans? J Immigr Minor Health. $2010 \cdot 12(3) \cdot 302-9$ 
40. Hsiao AF, Wong MD, Goldstein MS, Yu HJ, Andersen RM, Brown ER, et al. S: variation in complementary and alternative medicine (CAM) use across racial/ethnic groups and the development of ethnic-specific measures of CAM use. J Altern Complement Med. 2006;12(3):281-90.

41. Mengesha ZB, Perz J, Dune T, Ussher J. Refugee and migrant women's engagement with sexual and reproductive health care in Australia: $A$ socio-ecological analysis of health care professional perspectives. PLoS One. 2017;12(7):e0181421.

42. Solis JM, Marks G, Garcia M, Shelton D. Acculturation, access to care, and use of preventive services by Hispanics: findings from HHANES 1982-84. Am J Public Health. 1990;80:11-9.

43. Truter I. African traditional healers: cultural and religious beliefs intertwined in a holistic way. South Afr Pharm J. 2007;74(8):56-60.
44. Loue S. Gender, ethnicity, and health research: Springer Science \& Business Media; 1999

45. Barimah KB, Van Teijlingen E. R: the use of traditional medicine by Ghanaians in Canada. BMC Complement Altern Med. 2008;8(1):30.

46. Spector R. Heritage consistency: a predictor of health beliefs and practices. Recent adv Nurs. 1989;23:23-5.

\section{Publisher's Note}

Springer Nature remains neutral with regard to jurisdictional claims in published maps and institutional affiliations.
Ready to submit your research? Choose BMC and benefit from:

- fast, convenient online submission

- thorough peer review by experienced researchers in your field

- rapid publication on acceptance

- support for research data, including large and complex data types

- gold Open Access which fosters wider collaboration and increased citations

- maximum visibility for your research: over $100 \mathrm{M}$ website views per year

At BMC, research is always in progress.

Learn more biomedcentral.com/submissions 